\title{
Vascular effects of aqueous Crocus sativus petals' extract in the hypertensive rats
}

\author{
$\underline{\text { Khadijeh Farrokhfall }}^{\left({ }^{1} \text {, }\right.}$, Zahra Fatehi Hassanabad ${ }^{\left({ }^{2}\right.}{ }^{2}$, Zahra Gholamnejad ${ }^{\left({ }^{3}\right.}$
}

\begin{abstract}
Background and Aim: Crocus sativus (C. sativus) petals attenuates smooth muscle tension and blood pressure in control animals. However the antihypertensive effect and its mechanisms haven't been recognized. This study investigates the antihypertensive effects of $C$. sativus petals' aqueous extract in hypertensive rats and also responses of the rat isolated perfused mesenteric bed.
\end{abstract}

Materials and Methods: The interventional experimental study was performed on 20 male rats (divided to 5 and 15 rats for in vivo and in vitro studies respectively). Hypertension was induced by DOCA-salt injection $(20 \mathrm{mg} / \mathrm{kg}$, twice weekly, for 5 weeks, S.C) and water was replaced by $\mathrm{NaCl}(1 \%)$. Five weeks later, animals were anaesthetized with sodium thiopental (30 mg intraperitoneal). Then systemic arterial blood pressure was measured by cannulation of carotid artery following administration of different doses of aqueous extract of $C$. sativus. Isolated mesenteric beds precontracted with $\mathrm{KCl}(40 \mathrm{mM})$, and the tension was measured in presence of different concentrations of the aqueous extract. Finally, various doses of $C$. sativus extract were applied after incubation by L-NAME or indomethacin. The mesentry was perfused with pump and the recordings were done by physiograph.

Results: Mean arterial blood pressure in hypertensive rats was $231 \pm 6 \mathrm{mmHg}$. Administration of aqueous extracts of $C$. sativus reduced the blood pressure in a dose-dependent manner. In mesenteric beds preparation, addition of $\mathrm{C}$. sativus reduced the contractile effects of $\mathrm{KCl}$. Incubation with L-NAME but not indomethacin abolished hypotension effect of the extract.

Conclusion: It was proposed that the antihypertensive effects of C. sativus petals' extract are through the reduction in total peripheral resistance following nitric oxide production.

Key Words: Crocus Sativus Petals, Hypertension, Rat, Mesenteric Artery

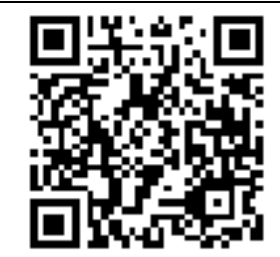

Citation: Farrokhfall Kh, Fatehi Hassanabad Z, Gholamnejad Z. [Vascular effects of aqueous Crocus sativus petals' extract in the hypertensive rats] J Birjand Univ Med Sci. 2020; 27(3): 265-274. [Persian].

DOI http://doi.org/10.32592/JBirjandUnivMedSci.2020.27.3.105

Received: July 17, 2019

Accepted: November 10, 2019

\footnotetext{
${ }^{1}$ Cardiovascular Diseases Research Center, Birjand University of Medical Sciences, Birjand, Iran

2 Imam Zaman Hospital, Mashad, Iran.

${ }^{3}$ Physiology Department, Faculty of Medicine, Mashad University of Medical Sciences, Mashad, Iran Corresponding author; Cardiovascular Diseases Research Center, Birjand University of Medical Sciences, Birjand, Iran. Tel: +985632381566 Fax: +985632433004 Email: kfarrokhfall@yahoo.com
} 


\section{بررسى اثرات عروقى عصاره آبى كلبر كى زعفران \\ در موش صحرايى با فشار خون بالا}

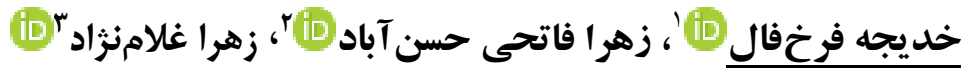

\section{جككيله}

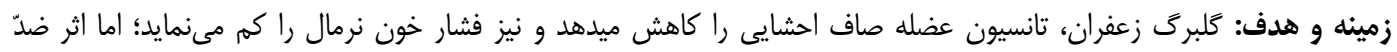

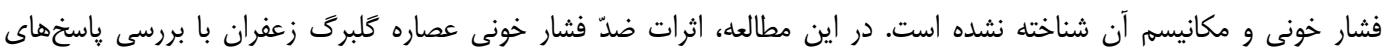

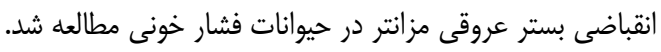

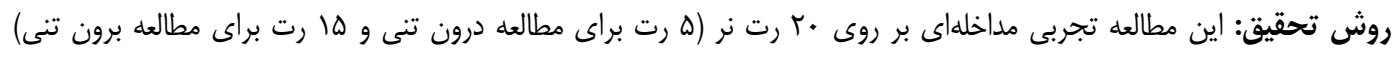

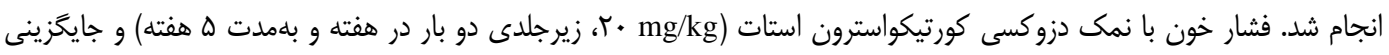

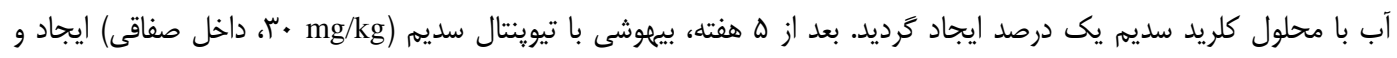

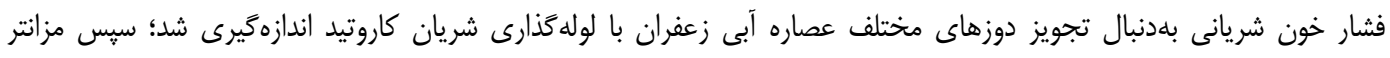

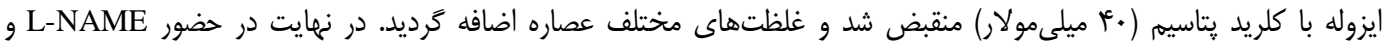

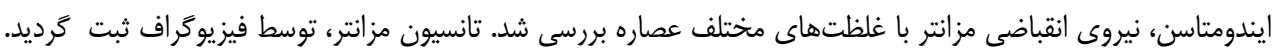

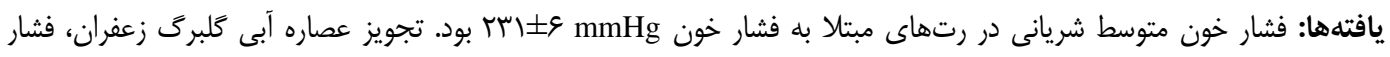

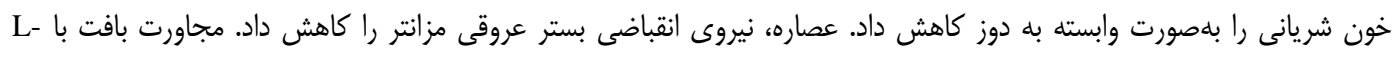

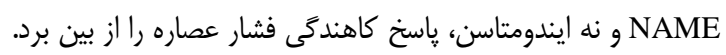

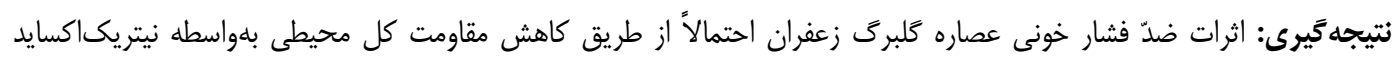
اعمال مى تردد. وازههاى كليدى: كلبرك زعفران، ير فشارى خون، رت، بستر عروقى مزانتر

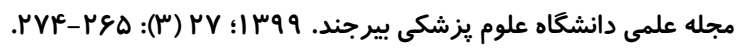
دريافت:

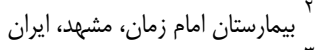

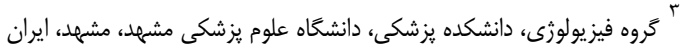

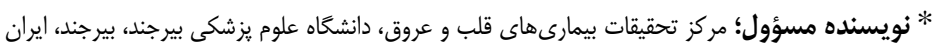

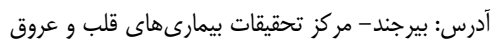

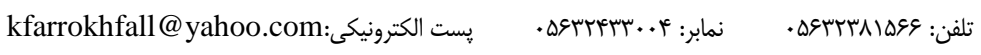


مثل قطعات برشخورده هندوانه بسيار مؤثرّ است (•(1). در مقل مله جستجوى مقالات در منابع علمى ،ما تنها يكى مطالعه را بيدا

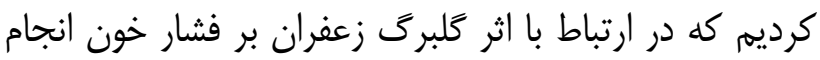

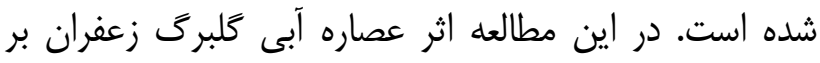
انقباض عضله صاف احشايى و فشار خون سيستميك مورد بررسى قرار كرفته است (1). در مطالعه اشاره شده مشخص

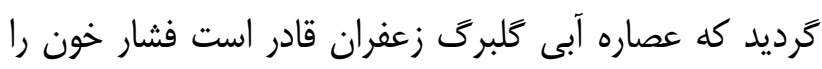

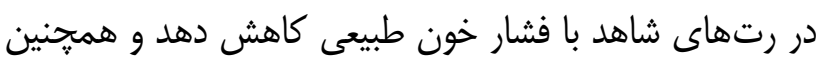

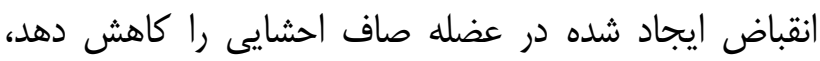

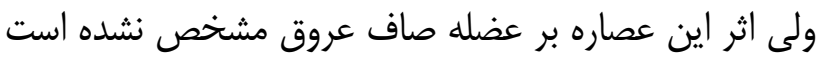

فشار خون شريانى بالا (هييرتانسيون')، مهمترين معضل

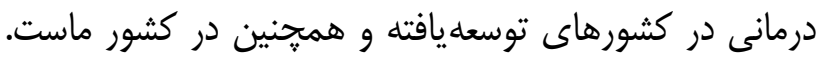

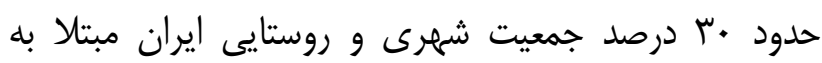

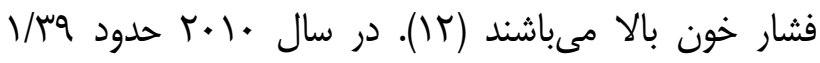

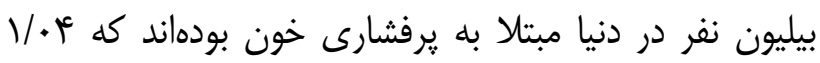

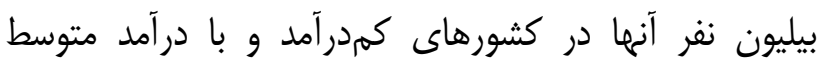

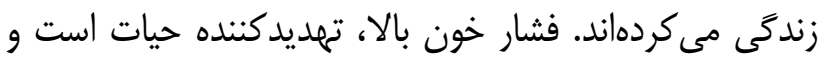

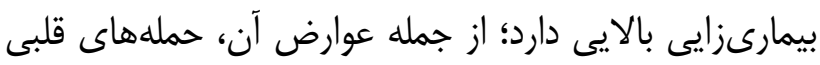
و مغزى است كه شايعترين علت مركى و مير در دنيا بهشمار إدارئ

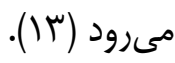

با وجود داروهاى متعدد ضدّ فشار خون، كنترل دقيق و

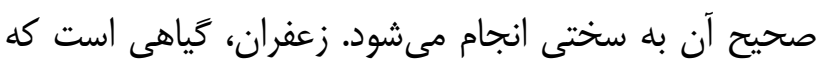

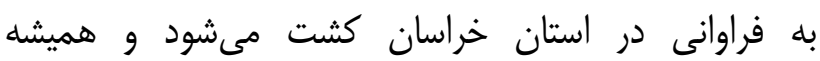

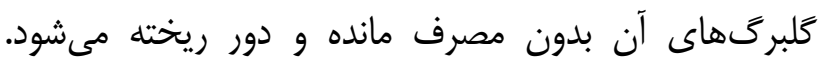

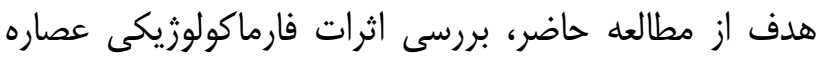

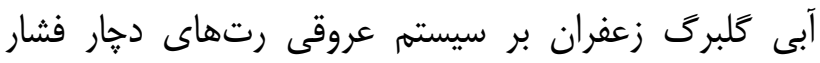

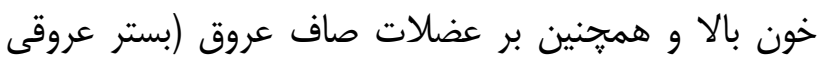
مزانتر) بود.

\footnotetext{
${ }^{1}$ Hypertension
}

زعفران (Crocus sativus) كَياهى جند ساله، به ارتفاع

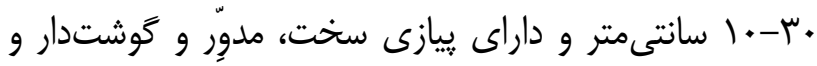

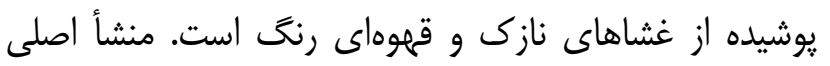

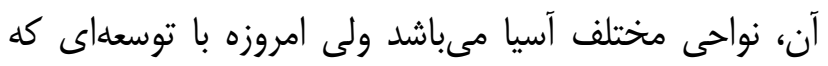

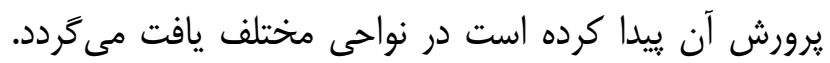
در ايران يرورش زعفران در نواحى مختلف خراسان صورت

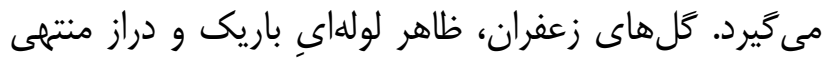

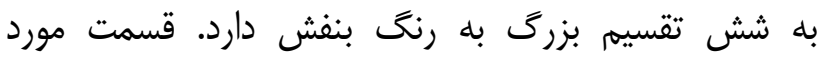
استفاده كياه، ناحيه انتهاى خامه و كلاله است كه تحت عند عندان

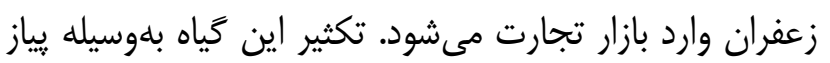
و در اواسط تيرماه صورت مى يَيرد (1). تاكنون مطالعات فراوانى بر روى زعفر دران النجان انجام شده و خواص درمانى متعددى به زعفران نسبت داده شده است (كان اندان

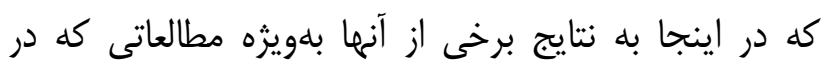

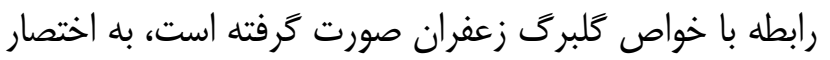

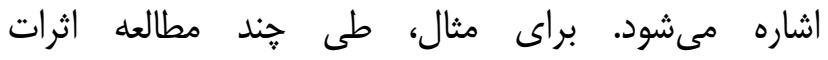

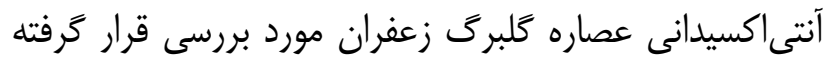

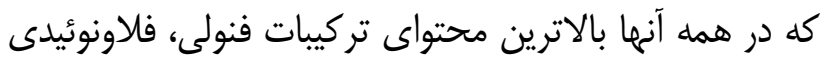

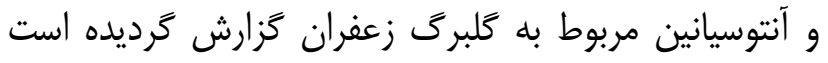

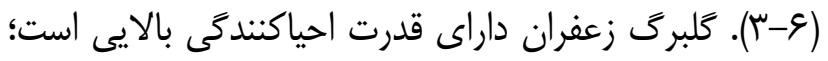

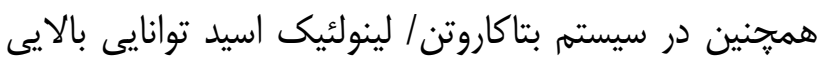

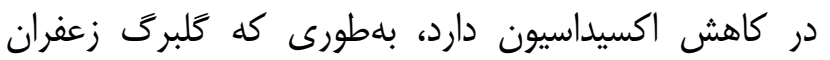

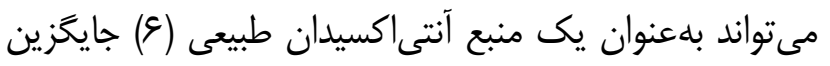

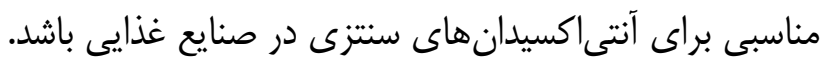

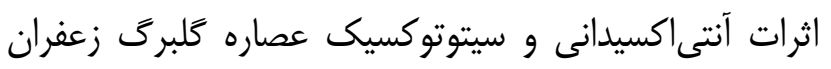

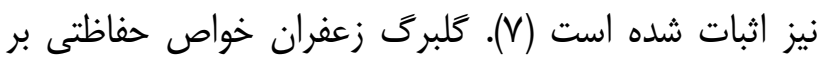

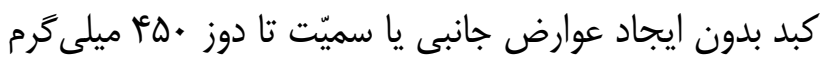

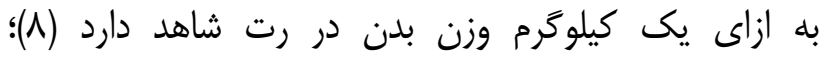
همجنين در رتهاى ديابتى با استريتوزوتوسين، سبب كاهش

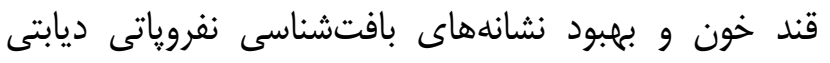

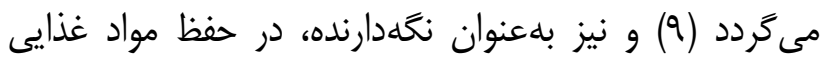


معرض غلظتهاى مختلف عصاره آبى كلبرى

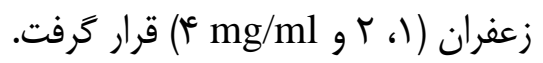

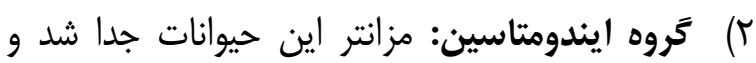

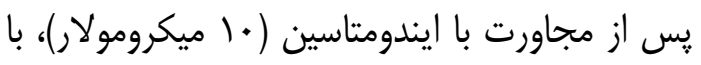

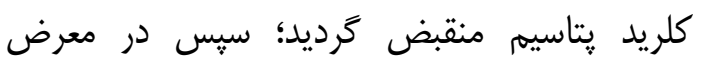

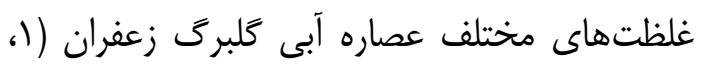

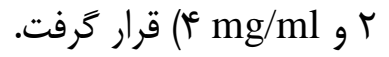

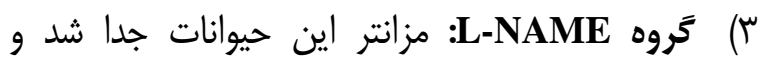
يس از مجاورت با L-NAME (... ميكرومولار)،

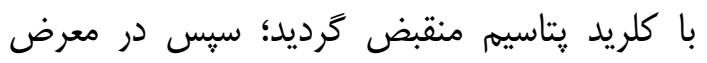

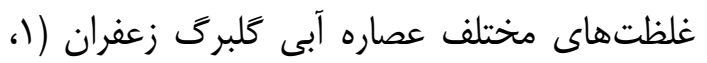

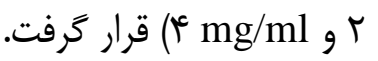

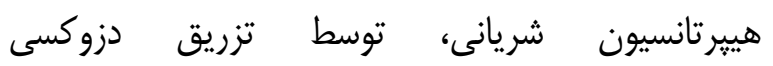

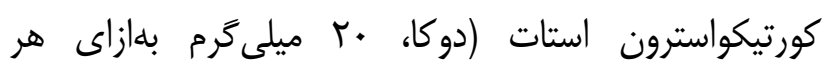

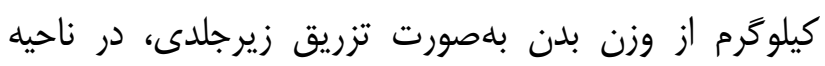

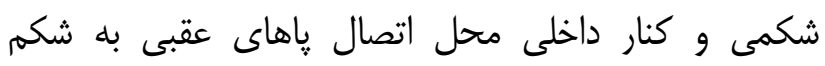

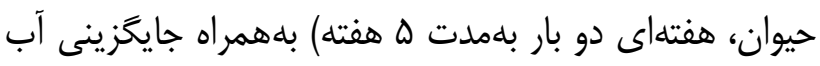
معمولى با آب حاوى نمك طعام (يك درصد) ايجاد كَرديد باري

در كل دوره آزمايش، حيوانات بلطور آزادانه به غذا و آب آب دئ

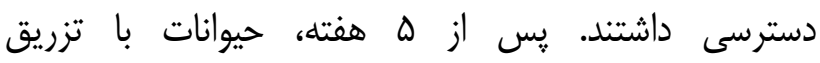

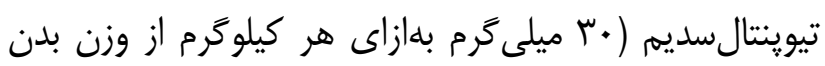

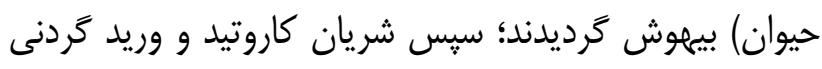

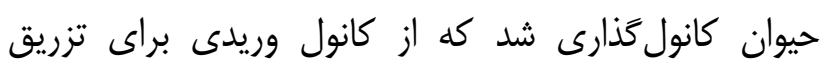

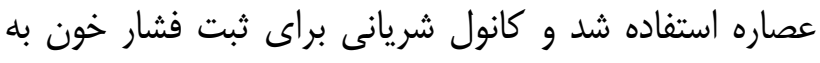

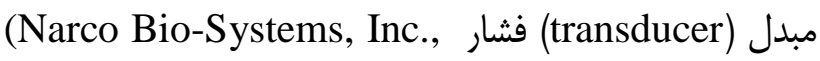
Houston, TX, USA) سيستول، فشار دياستول و نبض در تمامى حيوانات ثبت كرديد (IV)؛ سيس دوزهاى مختلفى از عصاره (به ترتيب: "آ،

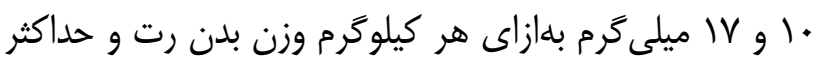

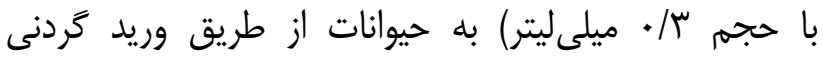
تزريق شد. قابل ذكر است ابتدا دوز كم تزريق و به دنبال از ازئ
روش تحقيق

در اين مطالعه، •ب عدد از موشهاى صحرايى نر نزاد Sprague-Dawley مؤسسه سرمسازى رازى مشهله، استفاده شد. حيوانات تا زمان

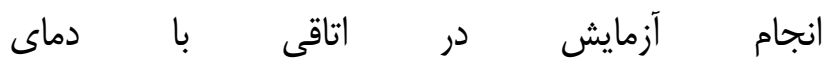

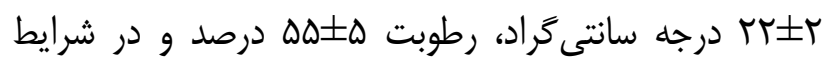

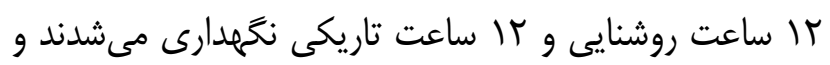

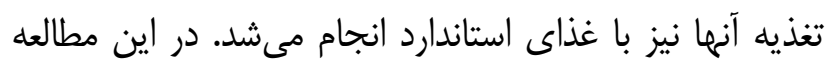

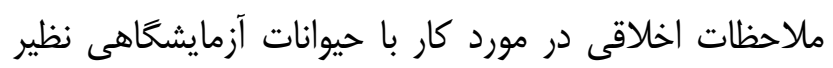

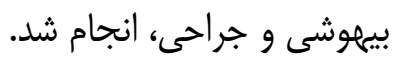

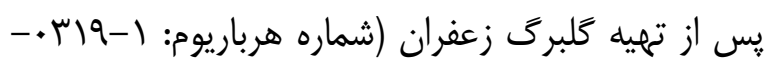

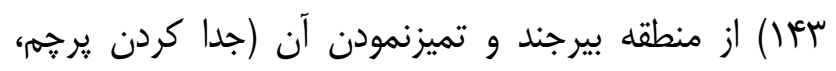

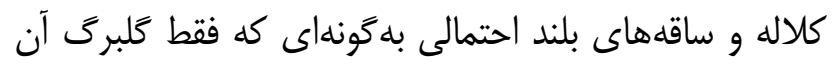

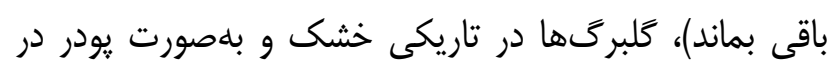

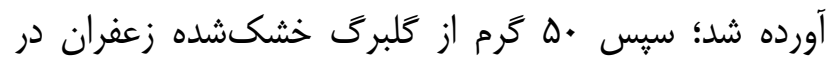

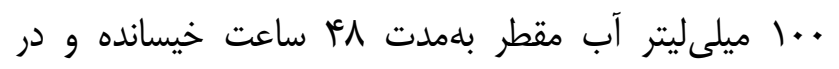

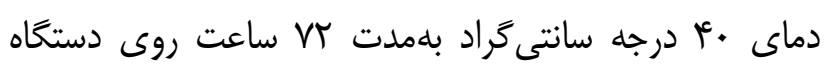

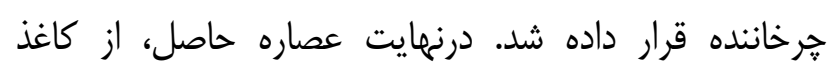

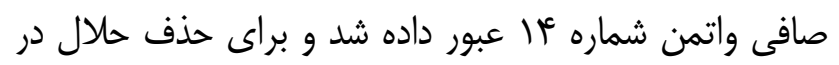

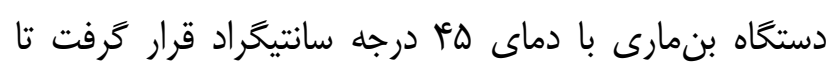
يودر خشكشده بلدست آيد (ألا، ها).

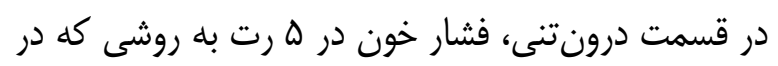

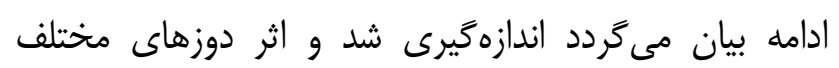

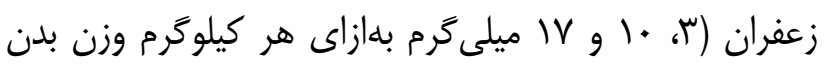

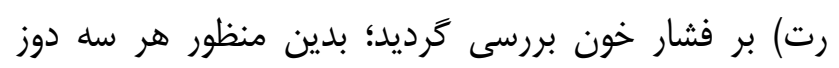

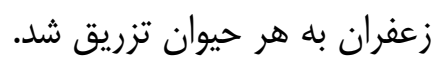

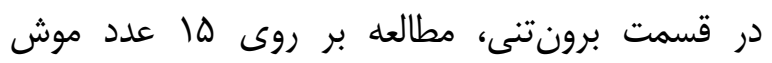

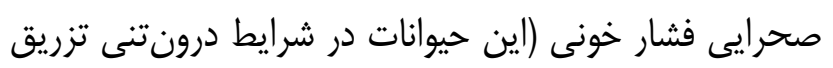

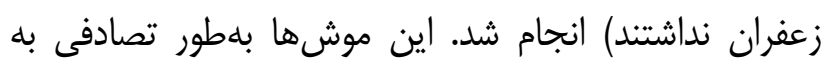

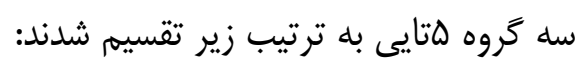

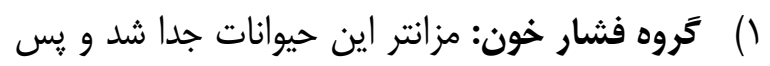

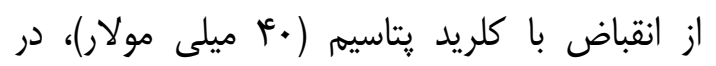


بافت بلهمدت + ب دقيقه در مجاورت ايندومتاسين با غلظت

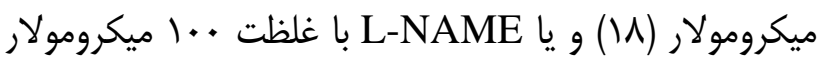

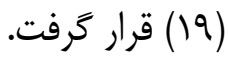
لازم به ذكر است داروهاى دزكسى كورتيكواسترون

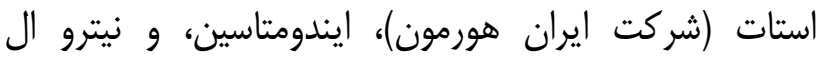

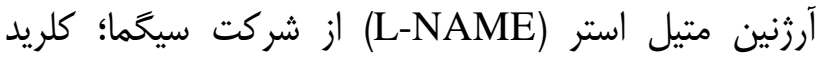
سديم، كلريد يتاسيه، منيزيهم سولفات، كربنات سديهم، كَلوكز،

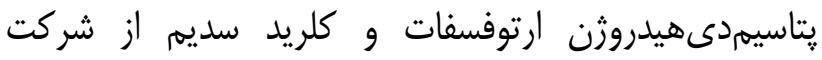
Merck اين آزمايش مورد استفاده قرار گرفتند. در اين آزمايش نتايج برحسب ميانخين لانحراف از معيار

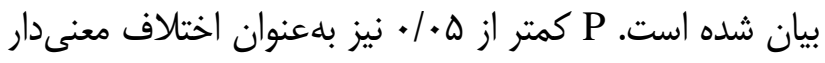

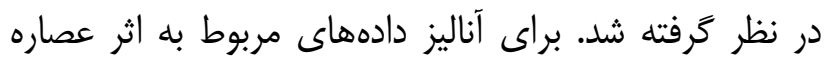
بر فشار خون متوسط شريانى و فشار يرفوزيون بستر عروقى لنى

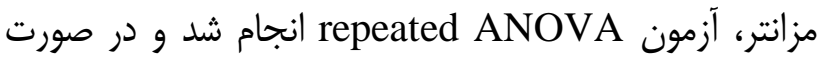
معنادار شدن، تست تعقيبى Bonferroni مورد استفاده قرار

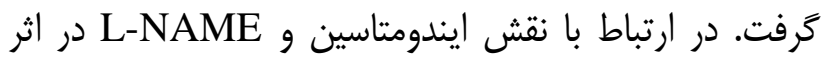
غلظتهاى مختلف عصاره بر فشار يرفوزيون مزانتر، آزمون two-way ANOVA Bonferroni Prism (ويرايش VPSS (ويرايش ه) صورت گرفت.

\section{يافته ها}

لبررسى اثرات عصاره آبى كَلبرَى زعفران بر فنشار خون و ضربانهاى قلبى حيوانات:

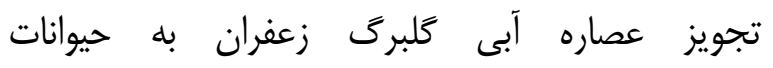

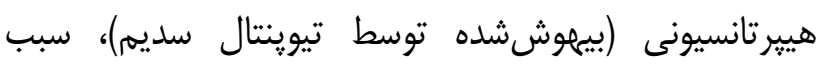
كاهش فشار خون شريانى (سيستوليك، دياستوليك و متوسط)

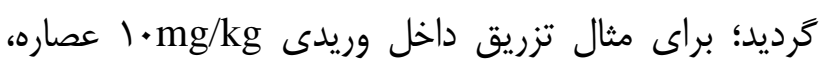

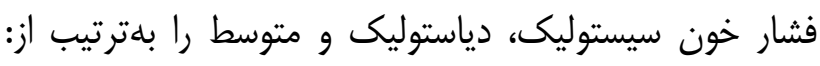
ع
بين رفتن اثر دارو و برگشت فشار خون به وضعيت قبل از تزريق ( تقريباً ٍس از • إدقيقه)، دوز بعدى تزريق كرديد.

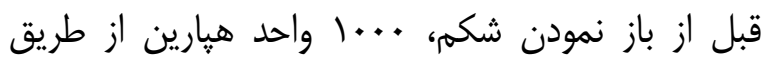

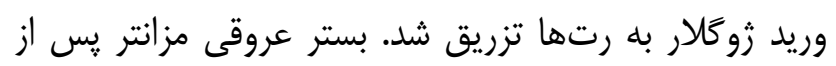

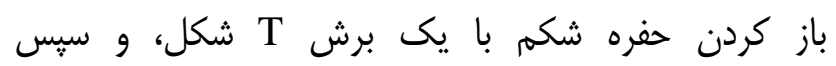

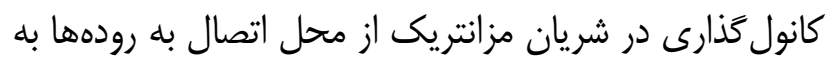

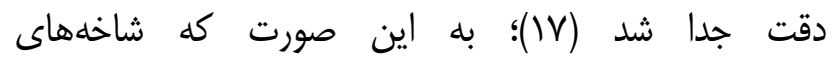
يانكراتيكودئودنال، ايليوكوليك و وكوليك شريان مزانت انتريك

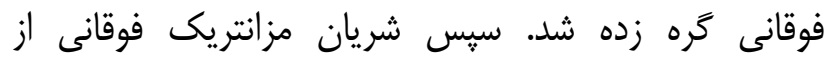

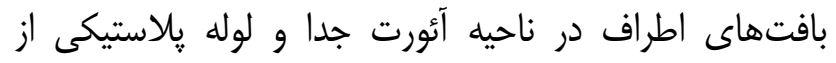

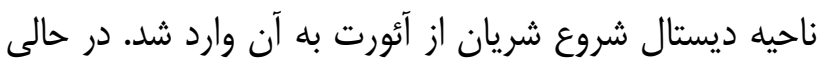

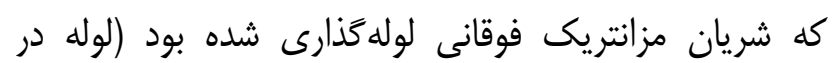

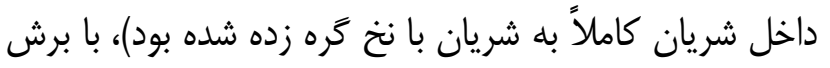

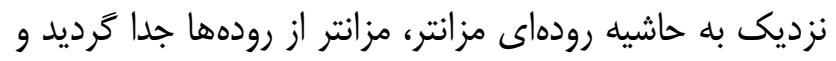

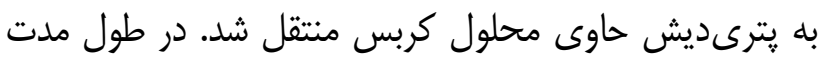

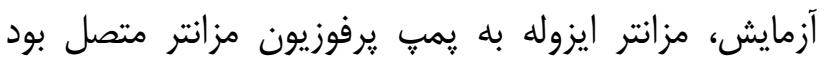
و و توسط (Gilson Minipuls 2, Villiers, France) كربس تغذيه مى

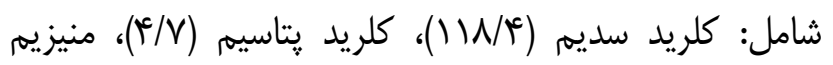

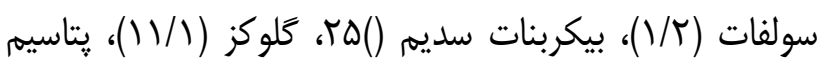

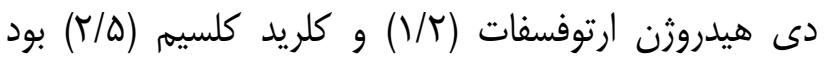

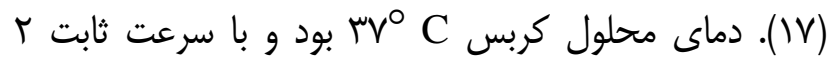

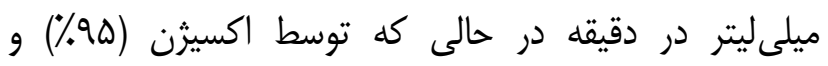

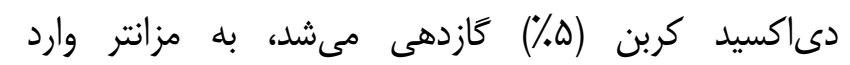

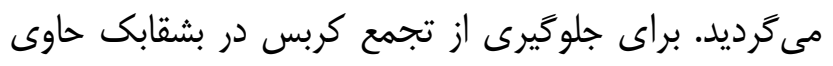

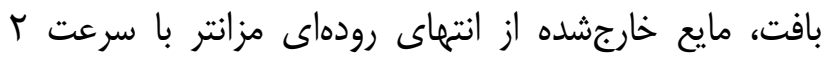

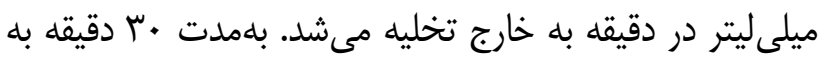

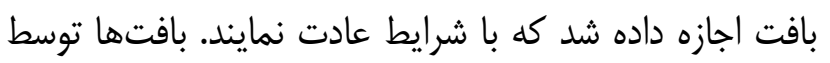

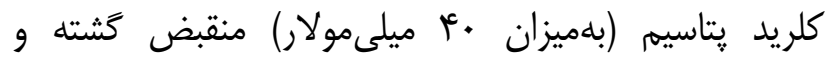
غلظتهاى متفاوتى از عصاره به كربس اضافه شد. براى

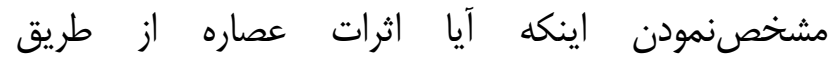

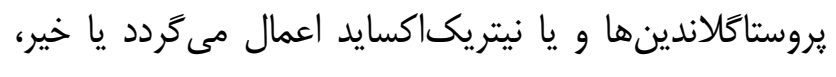



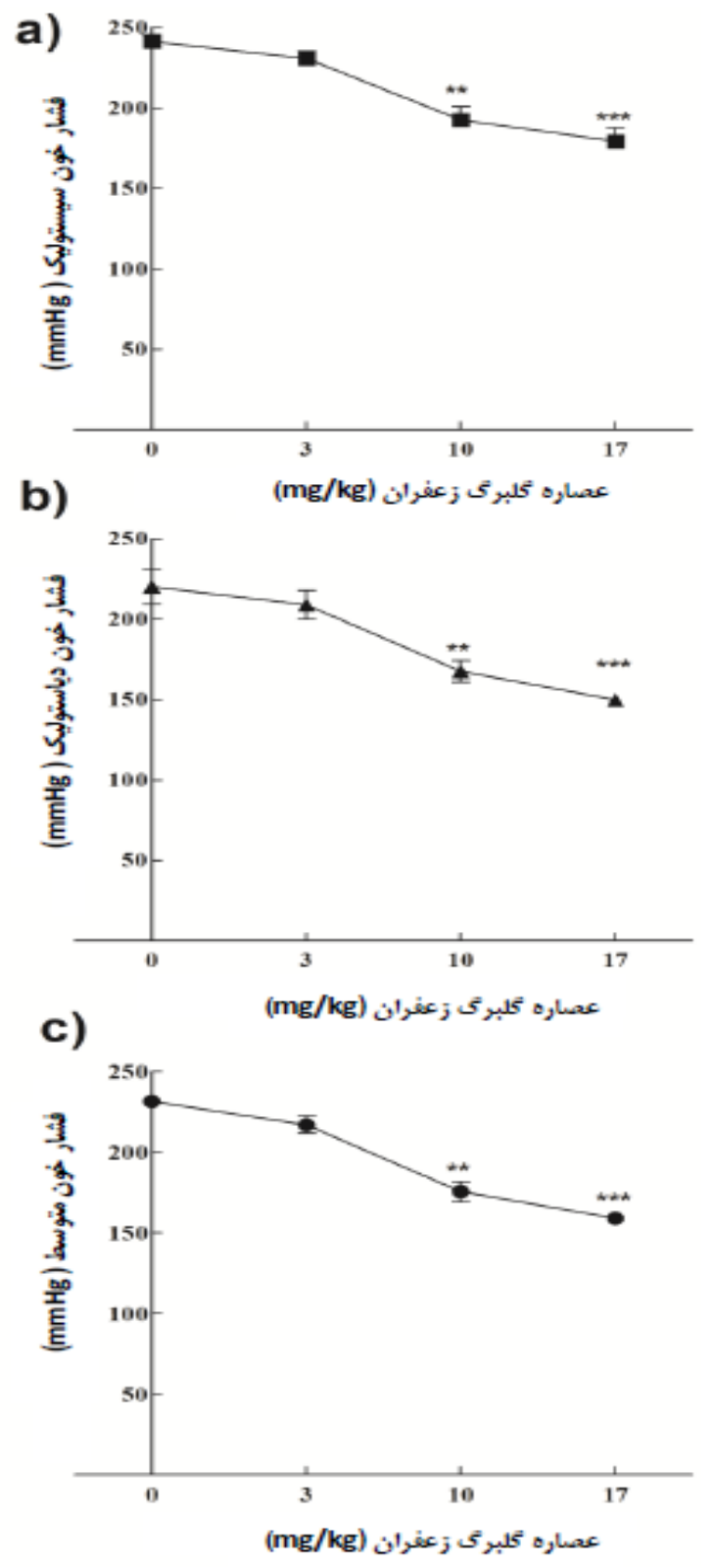

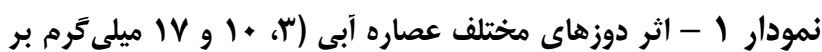

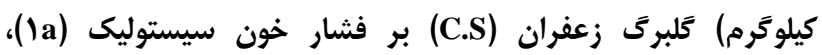

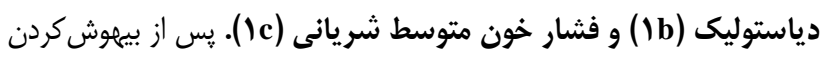

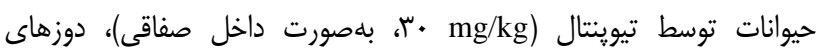

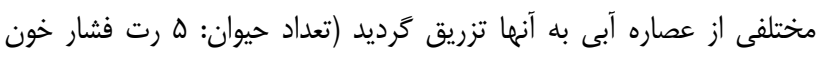

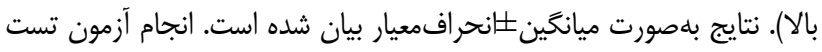

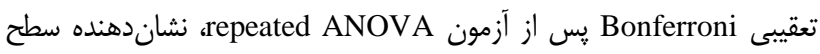

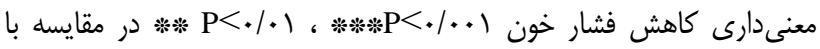

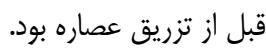

I I 19IN/D

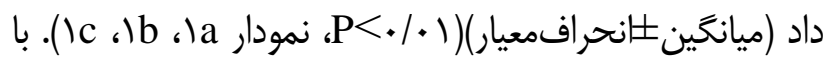
توجه به اينكه فشار خون متوسط شريانى در سيستم قلبى -

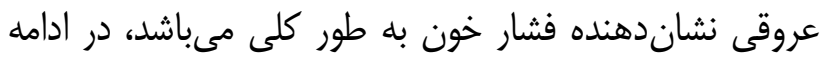
بيشتر در رابطه با فشار متوسط بحث مى نشود (حداكثر افت فشار در غلظت IVmg/kg ايجاد شده است). نبض حيو ديوانات

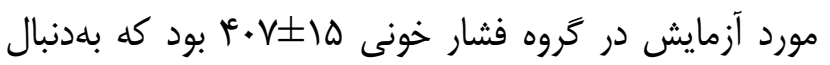

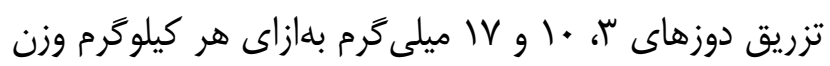

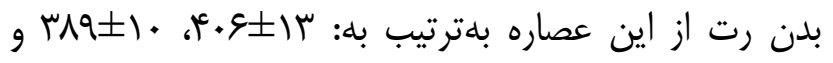

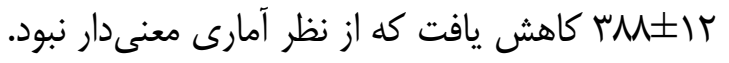

\بررسى اثرات عصاره آبى كَلبرَى زعفران بر بستر عروقى مزانتر:

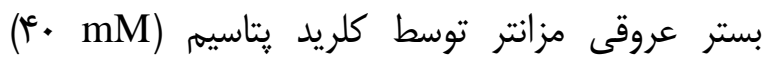

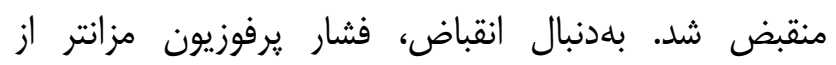

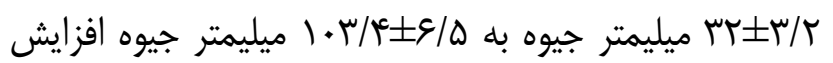

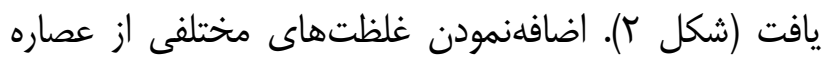
به كربس، سبب كاهش انقباض ناشى از كلريد يتاسيه گرديد؛

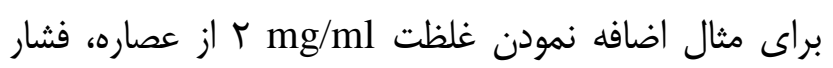

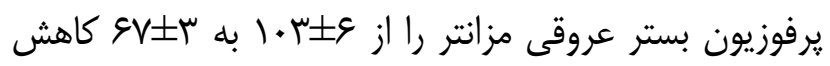

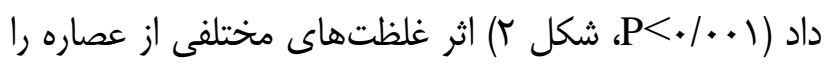
بر فشار يرفوزيون مزانتر نشان مىدهد. 


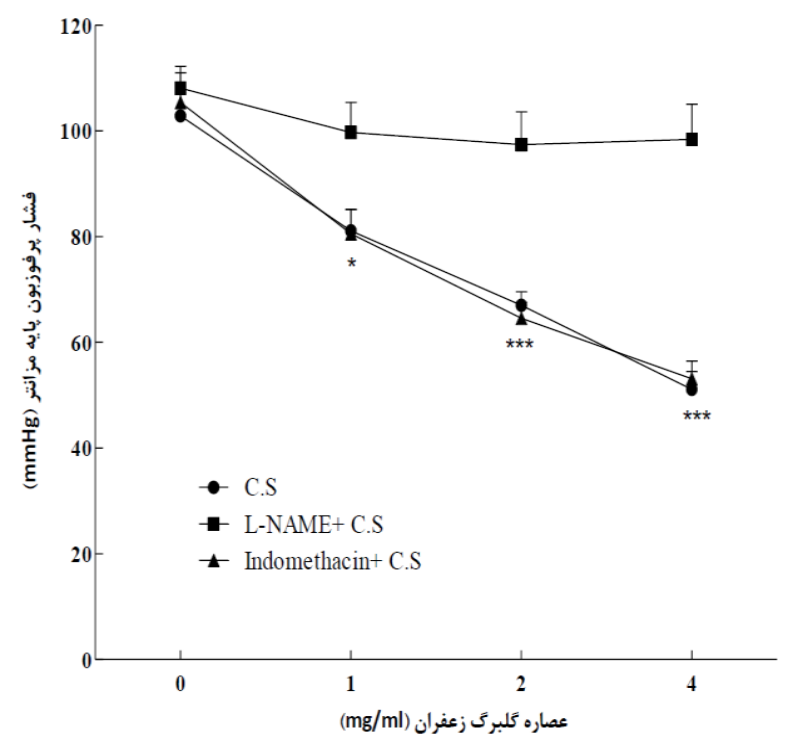

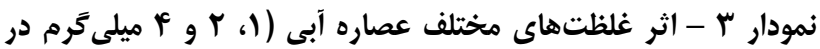

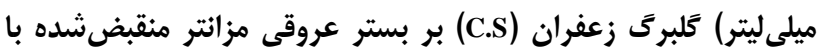

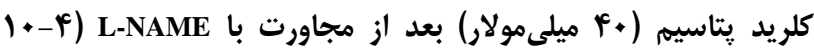

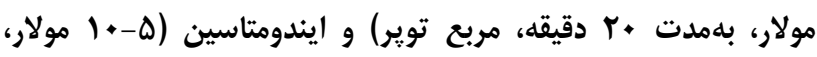

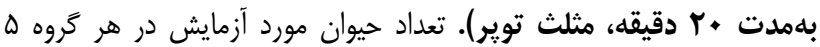

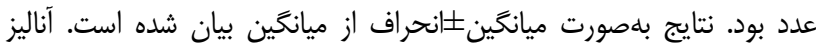

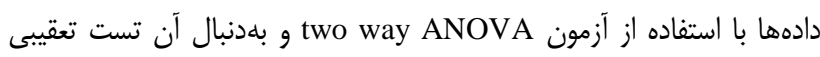

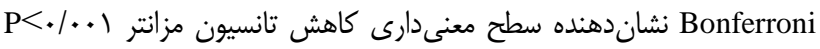

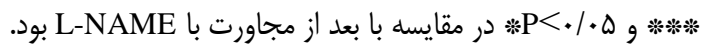

همانطور كه در قسمت نتايج اشاره شد تزريق داخل

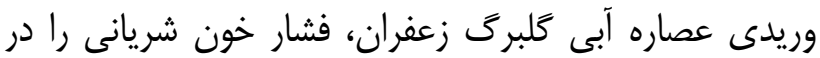

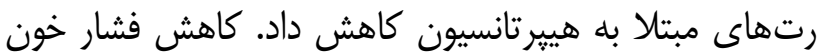
شريانى، با يك برادى كاردى غير معنىدار همراه بود كه با

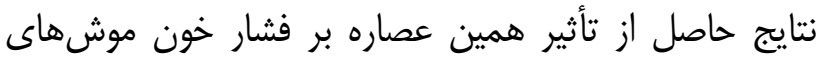

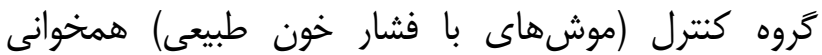
داشت. اين نتيجه با نتايج مطالعه ديخرى در اين زمينه همسو است (I)). اين كاهش فشار خون مىتواند ناشى از اثر عصاره

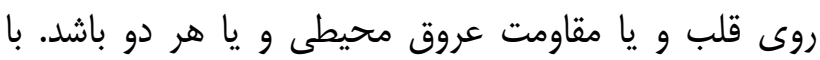

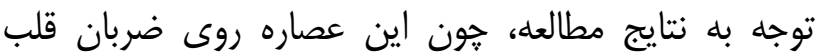

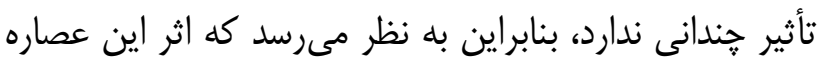
روى مقاومت عروق محيطى مهمتر باشد.

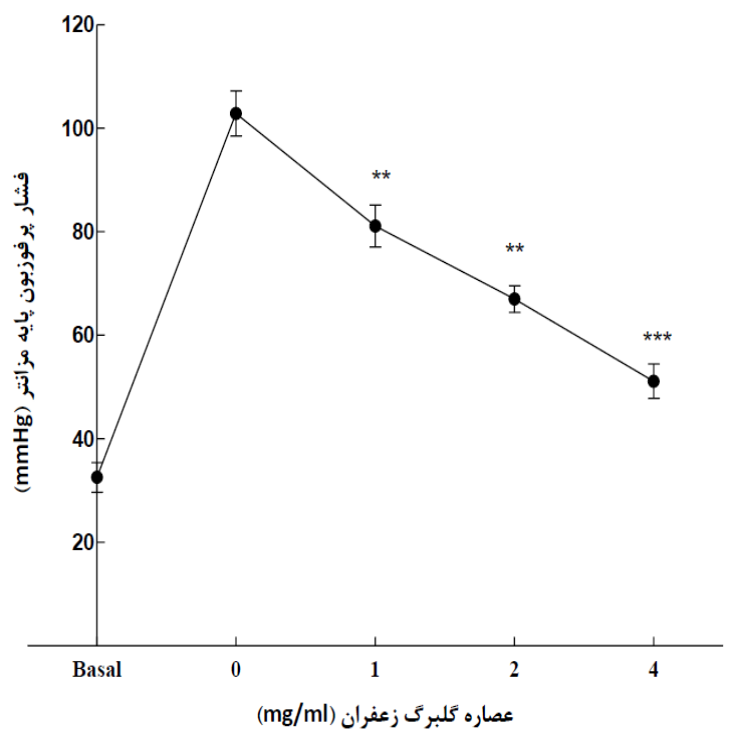

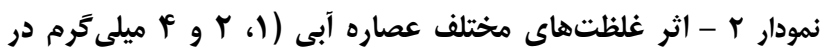

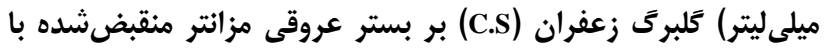

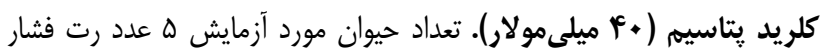

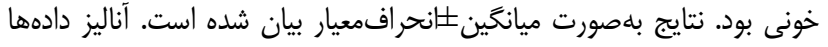

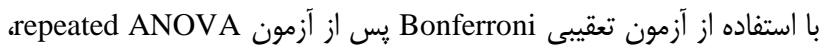

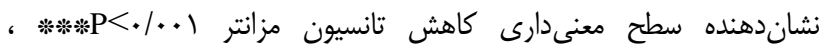

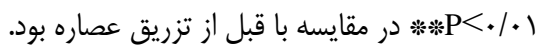

لبررسى اثرات عصاره آبى كَلبرَى زعفران بر بستر عروقى مزانتر در حضور ايندومتاسين و L-NAME: بستر عروقى مزانتر يس از مجاورت با ايندومتاسين

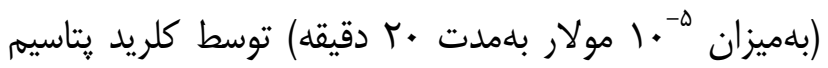
(l · mM)

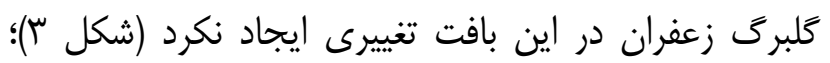

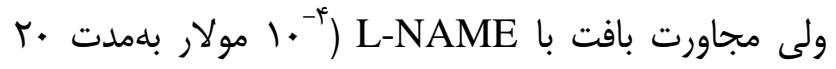

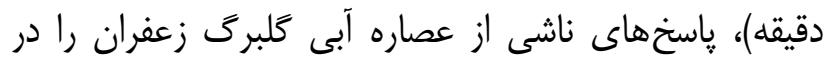
اين بافت كاهش داد (شكل ب اثر غلظتهاى مختلف عصاره ابى كاره

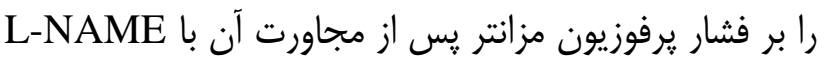
و ايندومتاسين و نيز بدون مجاورت با اين داروها نشان

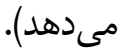




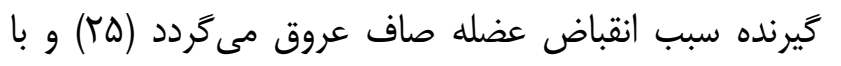

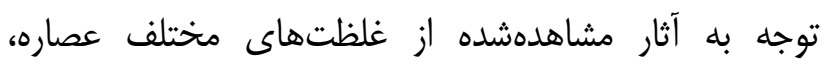

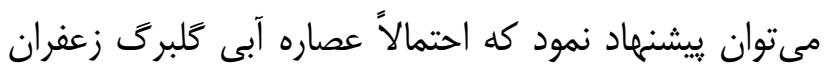

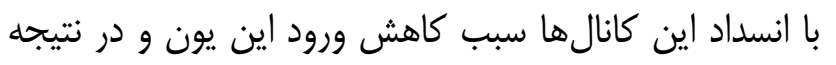

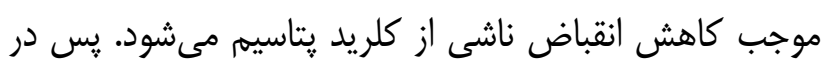

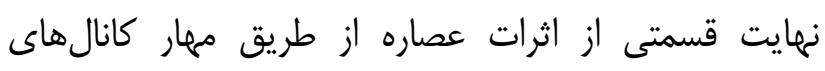

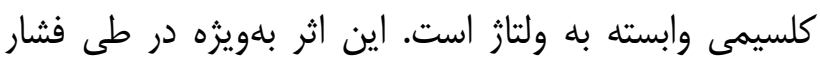

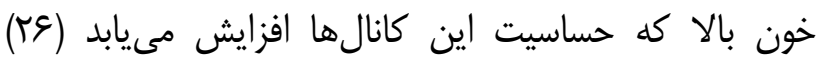
اهميت بيشترى دارد.

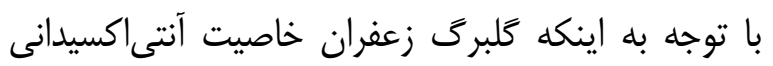

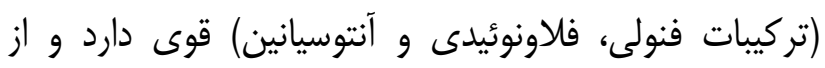

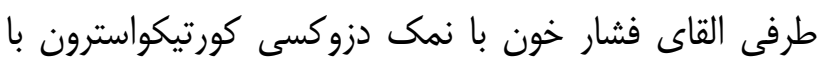

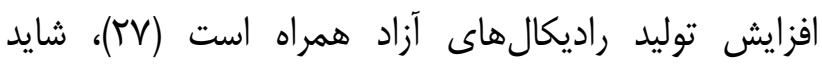

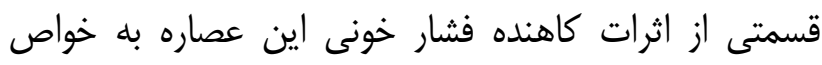
آنتى اكسيدانى آن مرتبط باشد.

\section{نتيجه كيرى}

به نظر مىرسد عصاره كلبرى زعفران از طريق مايق مسيرى

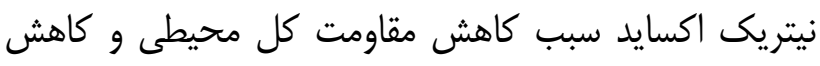

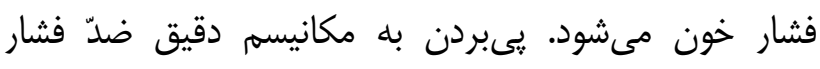

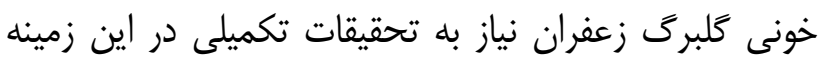

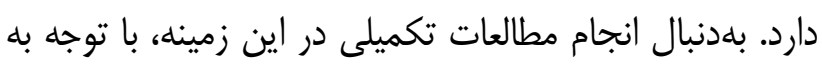

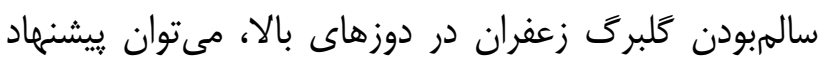
نمود كه در جريان هييرتانسيون مورد استفاده قرار كيردان

تقدير و تشكر اين مطالعه با كد طرح مصوب س...بر دانشعاه علوم يزشكى مشهد انجام شد.

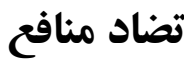

نويسندكان مقاله اعلام مىدارند كه هيج كَونه تضاد منافعى در يزوهش حاضر وجود ندارد.
همجنين در مطالعه حاضر عصاره آبى كلبرى زعفران،

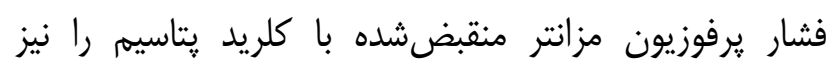

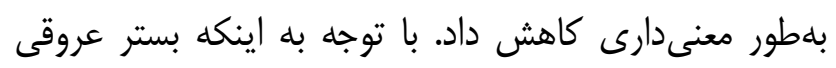

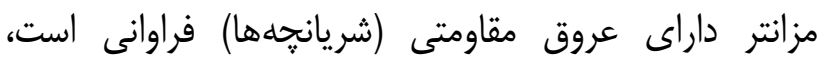

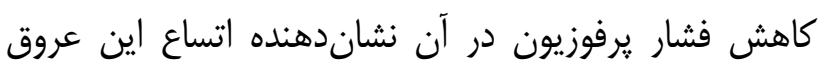

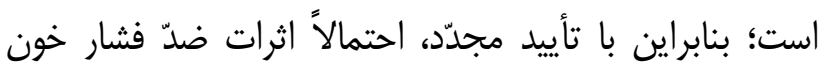

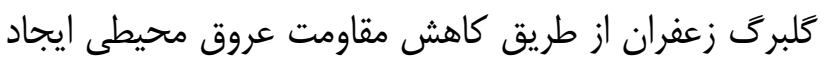

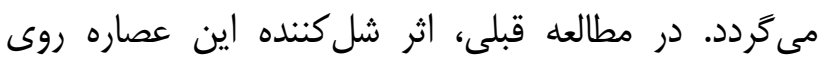

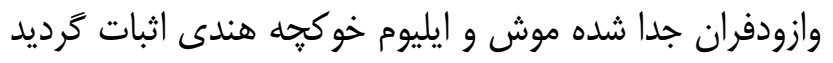

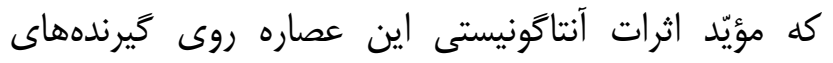

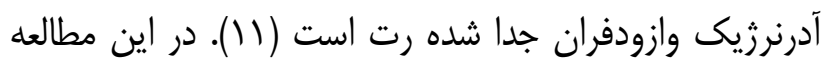

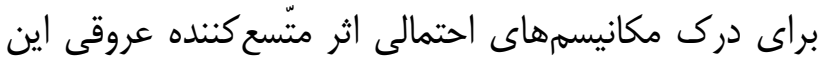

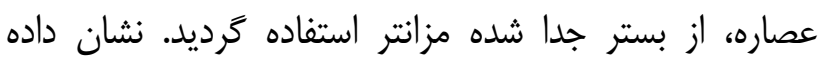

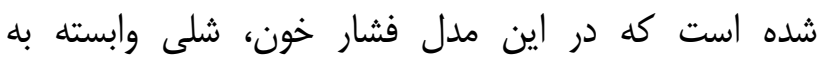

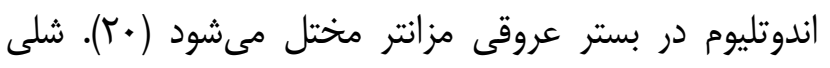

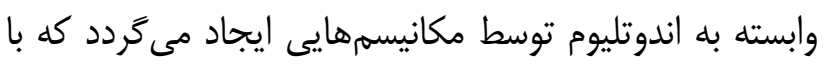

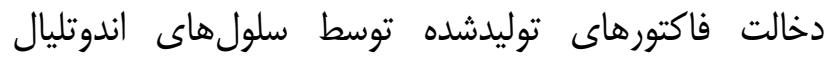

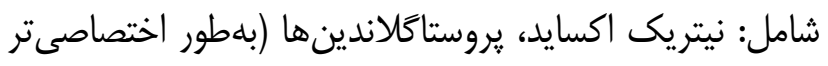

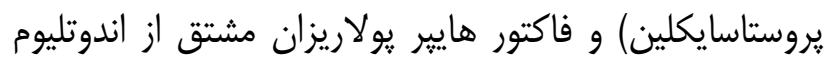
(EDHF)

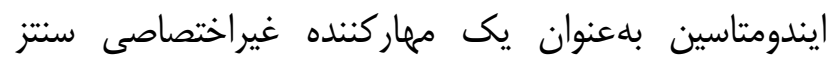

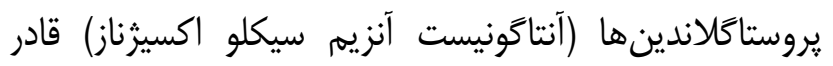

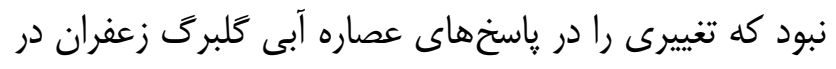

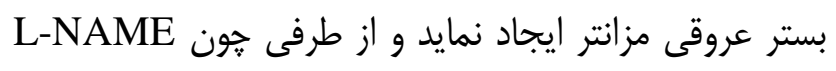

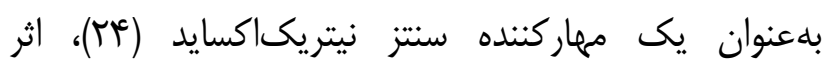

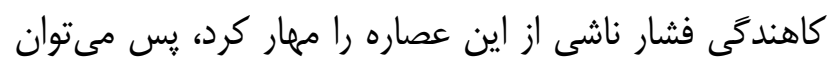

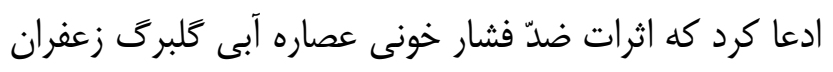

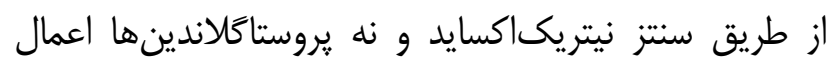

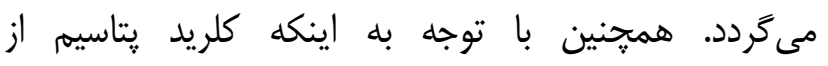

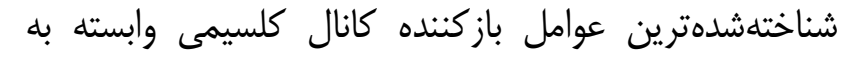
ولتاز مىباشد كه با اثر مستقيم بر عضله صاف و مستقل از از

${ }^{1}$ Endothelial Derived Hyperpolarizing Factor 
1- Zargari A. Medicinal plants. $6^{\text {th }}$ ed. Tehran: Tehran university publications; 1997. [Persian]

2- Srivastava R, Ahmed H, Dixit RK, Dharamveer, Saraf SA. Crocus sativus L.: A comprehensive review. Pharmacogn Rev. 2010; 4(8): 200-8.

3- Goupy P, Vian MA, Chemat F, Caris-Veyrat C. Identification and quantification of flavonols, anthocyanins and lutein diesters in tepals of Crocus sativus by ultra performance liquid chromatography coupled to diode array and ion trap mass spectrometry detections. Ind Crops Prod. 2013; 44: 496-510.

4- Jadouali SM, Atifi H, Mamouni R, Majourhat K, Bouzoubaâ Z, Laknifli A, et al. Chemical characterization and antioxidant compounds of flower parts of Moroccan crocus sativus L. Chemical characterization and antioxidant compounds of flower parts of Moroccan crocus sativus L. Journal of the Saudi Society of Agricultural Sciences. 2019; 18(4): 476-80. doi: 10.1016/j.jssas.2018.03.007

5- Montoro P, Maldini M, Luciani L, Tuberoso CI, Congiu F, Pizza C. Radical scavenging activity and LC-MS metabolic profiling of petals, stamens, and flowers of Crocus sativus L. J Food Sci. 2012; 77(8): C893-900. doi: 10.1111/j.1750-3841.2012.02803.x.

6- Zeka K, Ruparelia KC, Continenza MA, Stagos D, Vegliò F, Arroo RRJ. Petals of Crocus sativus L. as a potential source of the antioxidants crocin and kaempferol. Fitoterapia. 2015; 107: 128-34. doi: 10.1016/j.fitote.2015.05.014.

7- Tuberoso CI, Rosa A, Montoro P, Fenu MA, Pizza C. Antioxidant activity, cytotoxic activity and metabolic profiling of juices obtained from saffron (Crocus sativus L.) floral by-products. Food Chem. 2016; 199: 18-27. doi: 10.1016/j.foodchem.2015.11.115.

8- Babaei A, Arshami J, Haghparast AR, Danesh Mesgaran M. Effects of Crocus Sativus Petals Extracton Blood Parameters in Rat. J Arak Uni Med Sci. 2013;16(6): 14-21. [Persian]

9- Zarezadeh M, Vazifeshenas- Darmiyan K, Afshar M, Valavi M, Serki E, Hosseini M. Effects of Extract of Crocus sativus Petal on Renal Function in Diabetic Rats. J Mazand Univ Med Sci. 2017; 27(147): 11-24. [Persian]

10- Kaveh H. Effect of saffron petal extract on retention quality of fresh-cut watermelon cubes. Saffron Agronomy \& Technology. 2016; 4(4): 301-12. doi: 10.22048/jsat.2016.38667 .[Persian]

11- Fatehi M, Rashidabady T, Fatehi-Hassanabad Z. Effects of Crocus sativus petals' extract on ratblood pressure and on responses induced by electrical field stimulation in the rat isolated vas deferens and guinea-pig ileum. J Ethnopharmacol. 2003; 84(2-3): 199-203. doi: 10.1016/S0378-8741(02)00299-4 •

12- Delavari AR, Horri N, Alikhani S, Gouya MM, Mahdavi AR, Hosseini SM, et al. Prevalence of Hypertension in Iranian Urban and Rural Populations Aged over 20 years in 2004. J Mazandaran Univ Med Sci. 2007; 17(58): 7986. [Persian]

13- Mills KT, Bundy JD, Kelly TN, Reed JE, Kearney PM, Reynolds K, et al. Global Disparities of Hypertension Prevalence and Control. A Systematic Analysis of Population-Based Studies From 90 Countries. Circulation. 2016; 134(6): 441-50. doi: 10.1161/CIRCULATIONAHA.115.018912

14- Pajohi-Alamoti M, Yadollahi-baghloyi M, Bazargani-gillani B. The Effect of Water Extract of Rhus Coriaria L. on the Pathogenic Bacteria at Different Temperatures. J Babol Univ Med Sci. 2016; 18(2): 41-7. [Persian]

15- Shariat HS. Qualitative and Quantitative evaluation of the active Coxstiuents and control methodes for medicinal Plants. $2^{\text {nd }}$ ed. Esfahan: Mani publications; 2007. [Persian]

16- Bockman CS, Jeffries WB, Pettinger WA, Abel PW. Reduced contractile sensitivity and vasopressin receptor affinity in DOCA-salt hypertension. Am J Physiol Heart Circ Physiol. 1992; 262(6): H1752-8. doi: 10.1152/ajpheart.1992.262.6.h1752

17- Fatehi M, Anvari K, Fatehi-Hassanabad Z. The beneficial effects of protein kinase inhibition on the circulatory failure induced by endotoxin in the rat. Shock. 2002; 18(5): 450-5. doi: 10.1097/00024382-200211000-00011

18- Flower RJ. Drugs Which Inhibit Prostaglandin Biosynthesis. Pharmacol Rev. 1974; 26(1): 33-67. 
19- Amerini S, Mantelli L, Ledda F. Enhancement of the vasoconstrictor response to KCL by nitric oxide synthesis inhibition: A comparison with noradrenaline. Pharmacological Research. 1995; 31(3-4): 175-81. doi: 10.1016/1043-6618(95)80015-8

20- Adeagbo AS, Joshua IG, Falkner C, Matheson PJ. Tempol, an antioxidant, restores endothelium-derived hyperpolarizing factor-mediated vasodilation during hypertension. Eur J Pharmacol. 2003;481(1):91-100. doi: 10.1016/j.ejphar.2003.09.005

21- Goto K, Ohtsubo T, Kitazono T. Endothelium-Dependent Hyperpolarization (EDH) in Hypertension: The Role of Endothelial Ion Channels. Int J Mol Sci. 2018; 19(1): 315. doi: 10.3390/ijms19010315.

22- Lind L, Granstam SO, Millgård J. Endothelium-dependent Vasodilation in Hypertension: A Review. Blood Pressure. 2000; 9(1): 4-15.

23- Lind L. Lipids and endothelium-dependent vasodilation-A review. Lipids. 2002; 37(1): 1-15. doi: 10.1007/s11745-002-0858-6.

24- Moncada S, Palmer RM, Higgs EA. Nitric oxide: physiology, pathophysiology, and pharmacology. Pharmacol Rev. 1991; 43(2): 109-42.

25- Ratz PH, Berg KM, Urban NH, Miner AS. Regulation of smooth muscle calcium sensitivity: $\mathrm{KCl}$ as a calciumsensitizing stimulus. Am J Physiol Cell Physiol. 2005; 288(4):C769-83.

26- Jackson WF. Ion Channels and Vascular Tone. Hypertension. 2000; 35(1): 173-8. doi: 10.1161/01.HYP.35.1.173

27- Somers MJ, Mavromatis K, Galis ZS, Harrison DG. Vascular Superoxide Production and Vasomotor Function in Hypertension Induced by Deoxycorticosterone Acetate-Salt. Circulation. 2000; 101(14): 1722-8. doi: 10.1161/01.cir.101.14.1722. 